\title{
Increasing Redox Potential, Redox Mediator Activity, and Stability in a Fungal Laccase by Computer-Guided Mutagenesis and Directed Evolution
}

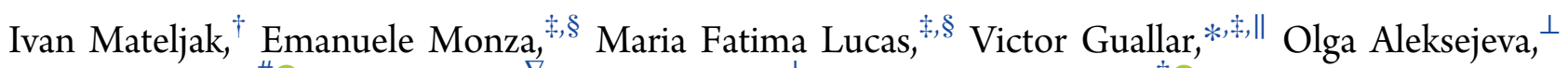
Roland Ludwig, ${ }^{\#(0)}$ Donal Leech, ${ }^{\nabla}$ Sergey Shleev, ${ }^{\perp}$ and Miguel Alcalde ${ }^{* \dagger}+(1)$

${ }^{\dagger}$ Department of Biocatalysis, Institute of Catalysis, CSIC, Cantoblanco, 28094 Madrid, Spain

${ }^{\ddagger}$ Barcelona Supercomputing Center, Jordi Girona 29, 08034 Barcelona, Spain

${ }^{\S}$ Zymvol, C/Almogavers 165, 08018 Barcelona, Spain

"ICREA: Institució Catalana de Recerca i Estudis Avancats, Passeig Lluís Companys 23, 08010 Barcelona, Spain

${ }^{\perp}$ Biomedical Sciences, Health and Society, Malmö University, 20560 Malmö, Sweden

\#Department of Food Sciences and Technology, VIBT-Vienna Institute of Biotechnology, BOKU-University of Natural Resources and Life Sciences, Muthgasse 18, 1190 Vienna, Austria

${ }^{\nabla}$ Department of Chemistry, National University of Ireland, Galway University Road, SW4 794 Galway, Ireland

\author{
Supporting Information
}

ABSTRACT: Fungal high-redox-potential laccases (HRPLs) are multicopper oxidases with a relaxed substrate specificity that is highly dependent on their binding affinity and redox potential of the $\mathrm{T} 1 \mathrm{Cu}$ site $\left(E_{\mathrm{T} 1}\right)$. In this study, we combined computational design with directed evolution to tailor an HRPL variant with increased $E_{\mathrm{T} 1}$ and activity toward high-redox-potential mediators as well as enhanced stability. Laccase mutant libraries were screened in vitro using synthetic highredox-potential mediators with different oxidation routes and chemical natures, while computer-aided evolution experiments were run in parallel to guide benchtop mutagenesis, without compromising protein stability. Through this strategy, the $E_{\mathrm{T} 1}$ of the evolved HRPL increased from 740 to $790 \mathrm{mV}$, with a concomitant improvement in thermal and acidic $\mathrm{pH}$ stability. The kinetic constants for high-redox-potential mediators were markedly improved and were then successfully tested within laccase mediator systems (LMSs). Two hydrophobic substitutions surrounding the $\mathrm{T} 1 \mathrm{Cu}$ site appeared to underlie these effects, and they were rationalized at the atomic level. Together, this study represents a proof-of-concept of the joint elevation of the $E_{\mathrm{T} 1}$, redox mediator activity, and stability in an HRPL, making this versatile biocatalyst a promising candidate for future LMS applications and for the development of bioelectrochemical devices.

KEYWORDS: laccase, redox potential, redox mediator, stability, directed evolution, computer-aided design

\section{INTRODUCTION}

Laccases (E.C. 1.10.3.2) are multicopper oxidases that catalyze the one-electron oxidation of a broad range of compounds, a process coupled to the four-electron reduction of molecular oxygen to water. The enzyme is organized into two catalytic copper centers: the $\mathrm{T} 1 \mathrm{Cu}$ site, where the substrate is oxidized, and the trinuclear $\mathrm{Cu}$ cluster-consisting of one $\mathrm{T} 2$ and two T3 coppers-where the reduction of molecular oxygen takes place. ${ }^{1,2}$ Predominantly distributed in higher plants, bacteria and fungi, laccases are classified for bioelectrochemical applications as low-, medium-, and high-redox-potential enzymes. This classification is based on the equilibrium potentiometric titrations of the redox potential at the $\mathrm{T} 1 \mathrm{Cu}$ site $\left(E_{\mathrm{T} 1}\right)$, ranging roughly from 0.43 to $0.79 \mathrm{~V}$ in reference to the NHE (normal hydrogen electrode). ${ }^{3-5}$ The $\mathrm{T} 1 \mathrm{Cu}$ site has a three coordinated trigonal planar structure in proteins with axial noncoordinating residues Phe or Leu (medium- and highredox-potential laccases) and a four coordinated trigonal elongated tetrahedral geometry in proteins with axial coordinating Met (low-redox-potential laccases from bacteria and plants). Moreover, this mononuclear copper site is wired to the $\mathrm{T} 2 / \mathrm{T} 3 \mathrm{Cu}$ cluster by a His-Cys-His tripeptide at a distance of ca. $12 \AA . .^{1,6-8}$

Received: February 4, 2019

Revised: April 11, 2019

Published: April 11, 2019 
High-redox-potential laccases (HRPLs) secreted by basidiomycete white rot fungi are particularly relevant in a biotechnological context given their capacity to oxidize compounds with a higher redox potential that cannot be transformed by their medium- and low-redox-potential counterparts. $^{2,9}$ In addition, HRPLs can be combined with redox mediators that act as diffusible electron shuttles between the enzyme and the oxidizable compound in the so-called laccase mediator systems (LMSs), thereby expanding the laccase substrate portfolio. ${ }^{10-12}$ As such, HRPLs have applications in bioremediation, synthetic chemistry, pulpbiobleaching, food, and textile industries. ${ }^{9,13-15}$ In addition, a high $E_{\mathrm{T} 1}$ offers an attractive set of advantages for engineering biodevices (biosensors and high-redox-potential enzymatic cathodes of biofuel cells), allowing the laccase to accept electrons directly from the cathode, to generate higher current densities, and to lower the overpotential for $\mathrm{O}_{2}$ reduction. ${ }^{4,16}$ Generally, electron transfer from the substrate to the $\mathrm{T} 1 \mathrm{Cu}$ is the rate-limiting step in laccase catalysis, highlighting the difference between the redox potential of the substrate and the $\mathrm{T} 1 \mathrm{Cu}$ as the main driving force for the reaction, together with the substrate binding affinity., $6,17-22$

The last couple of decades have witnessed an intense race to discover the factors responsible for the striking differences in $E_{\mathrm{T} 1}$ between laccases, mainly by focusing rational engineering enterprises on the coordination sphere of the $\mathrm{T} 1 \mathrm{Cu}$ and its surroundings. ${ }^{2}$ Modification of the $E_{\mathrm{T} 1}$ without endangering the enzyme's activity and stability has been pursued intensively by many laboratories around the world (including ours), albeit with little success. For example, mutagenesis studies were carried out to elucidate the effect of the axial ligand on $E_{\mathrm{T} 1}$. Accordingly, the mutations Phe463Met in Trametes villosa laccase and Leu499Met in Botrytis aclada laccase were shown to provoke a decrease in the redox potential of approximately $0.1 \mathrm{~V} \cdot{ }^{19,23}$ By contrast, the Met502Leu substitution in the bacterial CotA laccase increased the $E_{\mathrm{T} 1}$ by $0.1 \mathrm{~V}$, albeit at the expense of thermodynamic stability and poorer catalytic rates for all substrates tested. ${ }^{8}$ Alternatively, mutating the axial ligand from Leu to Phe in the low-redox-potential Myceliophthora thermophila laccase (MtL) did not produce significant changes in its enzymatic properties, including its redox potential, meaning that the nature of the axial ligand is not the only factor that affects $E_{\mathrm{T} 1} \cdot{ }^{6}$ The highly conserved tripeptide preceding the axial ligand Leu-Glu-Ala/ValSer-Gly (for high- and low-redox-potential laccases, respectively) was also switched between high- and low-redoxpotential laccases in the same study. While this modification significantly altered the laccases' enzymatic properties, the $E_{\mathrm{T} 1}$ remained unaffected. We later studied the complete VSG tripeptide in $\mathrm{MtL}$ by combinatorial saturation mutagenesis, and again the $E_{\mathrm{T} 1}$ was not modified. ${ }^{24}$ Laccase's $E_{\mathrm{T} 1}$ is regulated by many factors including the hydrophobicity in the milieu around the $\mathrm{T} 1 \mathrm{Cu}$ site and its particular coordinating geometry as well as hydrogen bonding, stacking and electrostatic interactions in the protein backbone, and restrictions in protein folding, such that any subtle modification of the $E_{\mathrm{T} 1}$ can disrupt the protein's normal functioning. ${ }^{7,25-28}$ Indeed, laccase-based catalysis is not fully understood yet since the process is complex and includes not only substrate oxidation at the $\mathrm{T} 1 \mathrm{Cu}$ site but also oxygen reduction, along with intramolecular electron transfer (IET) between the $\mathrm{T} 1 \mathrm{Cu}$ site and T2/T3 cluster. As the target value of $E_{\mathrm{T} 1}$ may also influence the rate of IET, a further increase in the $E_{\mathrm{T} 1}$ may result in a sluggish uphill IET, jeopardizing the overall biocatalytic reaction. Therefore, understanding how to modify the physicochemical features that influence the $E_{\mathrm{T} 1}$ of HRPLs without compromising their enzymatic activity and stability while defining the structural determinants behind such alterations remains a challenge, a holey grail for laccase engineers.

Here, we have increased the $E_{\mathrm{T} 1}$ of an HRPL, its activity toward high-redox-potential mediators, and its stability, by running both computer-aided evolution and in vitro directed evolution campaigns in parallel. A reliable high-throughput screening assay that combined two high-redox-potential mediators was adapted to screen in vitro mutant libraries toward a higher $E_{\mathrm{T} 1}$, while maintaining high activity and stability. After several rounds of laboratory evolution assisted by computationally guided mutagenesis, the final HRPL variant was biochemically, spectroelectrochemically, and computationally characterized at the atomic level. These findings are, to the best of our knowledge, the first experimental evidence of an enhancement in the $E_{\mathrm{T} 1}$ of an HRPL in conjunction with an improvement in its activity on high-redox-potential mediators and of its stability to temperature and acidic pHs.

\section{RESULTS AND DISCUSSION}

Computationally Guided Mutagenesis and Directed Evolution. The departure point in this study was an evolved laccase from basidiomycete PM1 that was isolated in the western Mediterranean region and that belongs to a group of HRPLs with strong thermostability. We previously submitted this HRPL to directed evolution to improve its functional expression in yeast, yielding the OB-1 variant used in the present study $^{29}$ (Figure S1). In this new directed evolution campaign, a high-throughput assay was developed on the basis of the oxidation of an inorganic transition metal complex, the redox mediator potassium octacyanomalybdate IV ( $\mathrm{K}_{4} \mathrm{Mo}$ $(\mathrm{CN})_{8}, E=0.78 \mathrm{~V}$ versus $\left.\mathrm{NHE}\right)$, to screen OB-1 mutant libraries for a higher $E_{\mathrm{T} 1}$. To avoid a substrate-dependent bias during screening, the assay was complemented with two colorimetric methods based on the oxidation of other synthetic mediators that acted as positive and negative selection controls, respectively: violuric acid, $E=0.92 \mathrm{~V}$ versus NHE; and ABTS (2,2'-azino-bis(3-ethylbenzothiazoline-6-sulfonic acid), $E=0.69 \mathrm{~V}$ versus $\mathrm{NHE}^{30}$ It is worth noting that violuric acid is a $\mathrm{N}-\mathrm{OH}$ mediator that follows the HAT (hydrogen atom transfer) mechanism, whereas $\mathrm{K}_{4} \mathrm{Mo}(\mathrm{CN})_{8}$, like ABTS, follows the ET (electron transfer) route yet without forming radicals since its electron exchange is centered on the metallic atom of the complex that contributes to high stability in both oxidation states. ${ }^{12}$ Screening assays were validated by establishing a coefficient of variance (16\%) and a reliable response, with high linearity from yeast supernatants produced in microcultures (i.e., 96-well plate format; Figure S2). Two consecutive rescreens were set up to limit the selection of false positives.

The whole evolution strategy is summarized in Figure S3. After applying distinct mutational loads and using polymerases with different biases (Figure S4), three independent mutant libraries were constructed and explored $(\sim 2400$ clones were screened). From this round of evolution, the L3G3 mutant (with Ala162Pro substitution) was identified that displayed a 1.7- and 1.3-fold improvement over the parental OB-1 for 

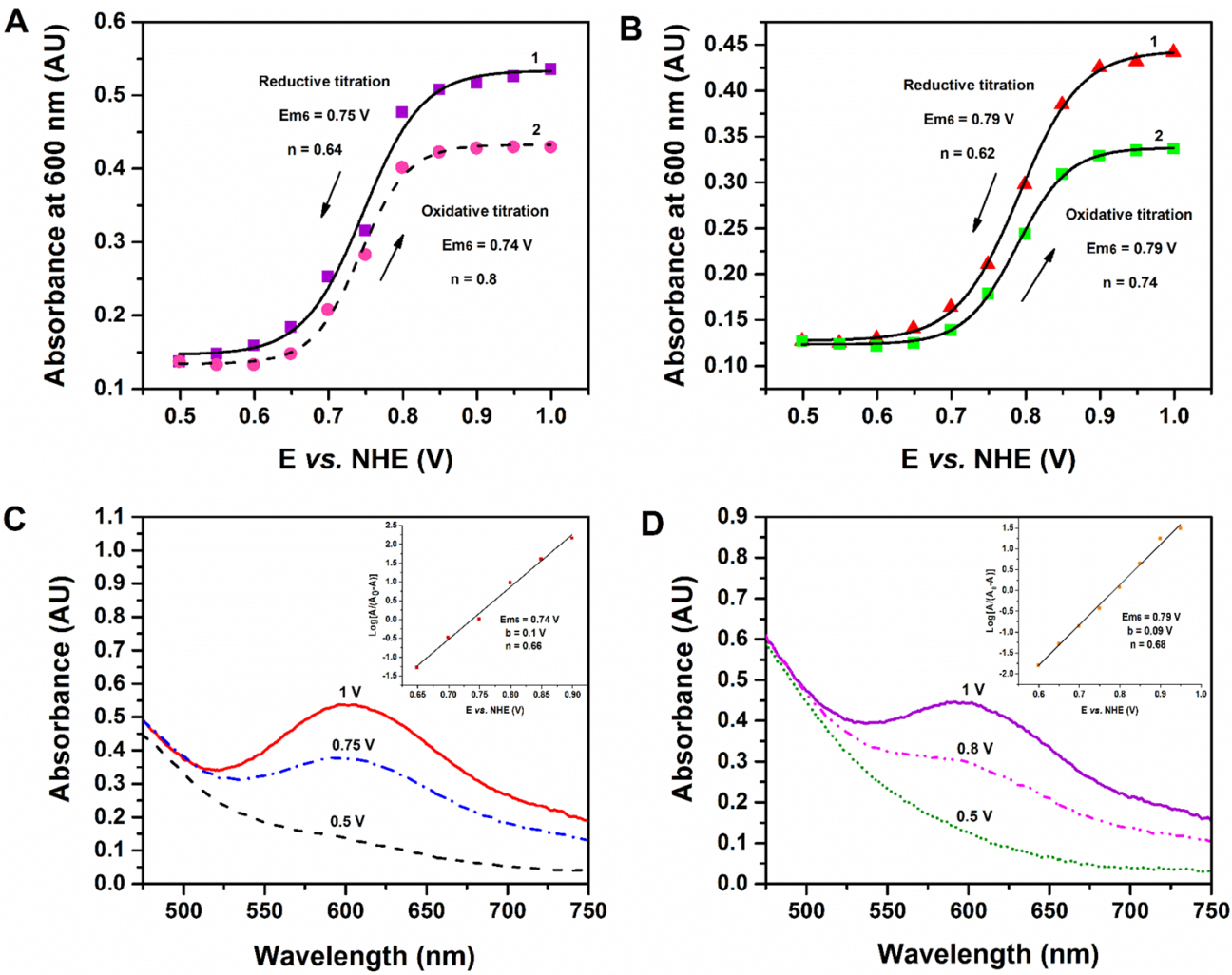

Figure 1. Spectroelectrochemical characterization. (A, B) Potentiometric titration curves: 1, reductive titration; 2, oxidative titration; for the parental OB-1 and the GreeDo mutant, respectively. (C, D) Spectra from the reductive titration, corresponding to the oxidized enzyme (1.0 V), the partly oxidized protein $(0.8$ and $0.75 \mathrm{~V})$, and the fully reduced laccase $(0.5 \mathrm{~V})$, for the parental OB-1 and GreeDo mutant, respectively. Inset: typical Nernst plot of the dependence of the applied potential on the absorbance at $600 \mathrm{~nm}$ and the average parameters calculated from the titrations. Em6, midpoint redox potential; $b$, slope of the titration curve, determined from linear fit; $n$, number of electrons involved in redox reactions.

$\mathrm{K}_{4} \mathrm{Mo}(\mathrm{CN})_{8}$ and violuric acid, respectively, while its activity on ABTS was reduced by $\sim 20 \%$.

With the aim of retrieving cooperative mutations, in parallel to the in vitro evolution experiment, we ran a new theoretical aided evolution approach. This computational method is based on ranking sequence positions instead of point mutations, ordering them according to the frequency of beneficial mutations. False positives are not filtered out since a position is chosen rather than a given mutation. We run this protocol based on violuric acid docking on the laccase model. For this in silico round, over 40 positions, all within $10 \AA$ from the substrate, were screened by molecular modeling, employing PELE (Protein Energy Landscape Exploration), a Monte Carlo algorithm capable of effectively sampling the protein-ligand conformational space. ${ }^{31}$ The screening process was based on identifying those positions that (after mutation) improved the protein-ligand interaction energy when using an oxidized substrate as a probe, in our case oxidized violuric acid (Figure S5). Thus, by enhancing the protein-product interaction, we aim to improve the thermodynamics of the reaction by helping to reduce the electron transfer transition state barrier (following Hammond's postulate). As a result, nine positions were identified. Importantly, one of the top 5 positions agreed with position 162 (ranking 3 ), which had been identified by the experimental parallel study, in an L3G3 variant (with Ala162Pro mutation). In addition, we selected position 458 (ranking 1) that had more beneficial (stabilizing) substitutions.

These two positions (Ala162 and Ala458) were then subjected to experimental combinatorial saturation muta- genesis, which generated a double mutant, Ala162ValAla458Leu (referred to as GreeDo) with a 2.5- and 4.8-fold improvement in activity toward $\mathrm{K}_{4} \mathrm{Mo}(\mathrm{CN})_{8}$ and violuric acid, respectively, and only a minor decrease in its activity on ABTS $(\sim 0.8$-fold $)$. Other double variants were identified in the same screening with slightly milder improvements in activity, for example, Ala162Asn-Ala458Arg with 2.3-, 1.5-, and 0.9-fold improvements in activity on $\mathrm{K}_{4} \mathrm{Mo}(\mathrm{CN})_{8}$, violuric acid, and ABTS, respectively; and Ala162Ile-Ala458Leu with 1.8-, 3.7-, and 0.7 -fold improvements, respectively, although they were not further characterized given their low stability (Figure S3). Given that GreeDo outperformed these counterpart double mutants in terms of activities and stabilities, we centered the ensuing evolution on this template. First, we constructed independent saturation mutagenesis libraries on Pro160 and Ile452. Position 160 (ranking 4), belonging to the loop 159164 (Figures S3 and S5), was identified by PELE. By contrast, Ile452 was not unveiled by PELE, but it was selected for mutagenesis due to its proximity to the $\mathrm{T} 1 \mathrm{Cu}(3.5 \AA)$ and to the sulfur atom of the coordinating Cys450 (4.0 $\AA)$. Unfortunately, after exploring both positions, we did not find any positive variant. Thereafter, we applied focused random mutagenesis and DNA recombination by MORPHING within a specific protein segment in the vicinity of the $\mathrm{T} 1 \mathrm{Cu}$ (Leu383-Thr461). ${ }^{32}$ The Leu383-Thr461 segment contains loop 388-389 identified through in silico experiments (Figure S5) and also includes an $\alpha$ helix in the vicinity of T1Cu where the 456Leu-Glu-Ala458 tripeptide is located, which is a highly conserved motif of HRPLs. However, this set of 
experiments did not yield any further improvement. Accordingly, after screening $\sim 6000$ clones in several rounds of evolution, the parental OB-1 and the GreeDo mutant were produced, purified to homogeneity, and characterized thoroughly.

Spectroelectrochemical, Biochemical, and Computational Characterization. Spectroelectrochemical Studies. To assess the change in the redox potential produced by directed evolution, the parental OB-1 and the GreeDo laccase variant were characterized electrochemically by open-circuit potential measurements combined with mediated spectroelectrochemical redox titrations, using the protocol developed previously. $^{33,34}$ First, open-circuit potentials (OCPs) of laccase-modified graphite electrodes were measured (Table S1 and Figure S6). The OCP of the GreeDo mutant increased over $30 \mathrm{mV}$ compared to that of OB-1 laccase (from 0.76 up to $0.79 \mathrm{~V})$. Taking into account the equilibrium redox potential of the oxygen/water couple equal to $0.87 \mathrm{~V}$ at $\mathrm{pH} 6.0,25^{\circ} \mathrm{C}$, the OCP value of $0.79 \mathrm{~V}$ is extraordinarily high since it implies only a $0.08 \mathrm{~V}$ overpotential $(\eta)$ for the oxygen reduction reaction. Moreover, OCP and $\eta$ values of GreeDo-modified graphite electrodes are identical to or even higher than these potentials measured for laccase-modified graphite electrodes using enzymes with the highest $E_{\mathrm{T} 1}$ reported to date. ${ }^{4}$ Second, $E_{\mathrm{T} 1}$ values of both enzymes were accurately determined. The $E_{\mathrm{T} 1}$ of the GreeDo mutant increased over $50 \mathrm{mV}$ compared to that of OB-1 laccase (from 0.74 to $0.79 \mathrm{~V}$; Figure 1A-D, Table S2). The engineering deployed in our studies allowed us to artificially match the highest redox potential of the $\mathrm{T} 1 \mathrm{Cu}$ site,

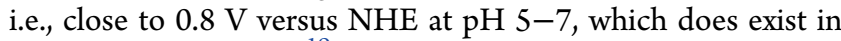
some native laccases. ${ }^{19}$ On one hand, this "natural" value seems to stand as a limit to the enzyme evolution, when it comes to $E_{\mathrm{T} 1}$. On the other hand, taking into account the equilibrium redox potential of the oxygen/water couple, viz. $0.88 \mathrm{~V}$ at $\mathrm{pH} 6$ with $59 \mathrm{mV} / \mathrm{pH}$ dependence and only a slight $\mathrm{pH}$ dependence of $E_{\mathrm{T} 1}$, i.e., $10-25 \mathrm{mV} / \mathrm{pH}$, a further enhancement of $E_{\mathrm{T} 1}$ of multicopper oxidases (MCOs) might still be doable. ${ }^{35-37}$ Furthermore, encouraging results related to azurin, a single copper protein, were reported recently, where the authors achieved fine-tuning of $E$ that spanned the entire range of physiological $E$ from +0.970 to $-0.954 \mathrm{~V}$ versus NHE, exceeding the $E$ of natural mononuclear cupredoxin by $\sim 0.3 \mathrm{~V}$, opening the possibility that these results could be translated in multicopper proteins. ${ }^{38}$ Nevertheless, to the best of our knowledge, this is the first time that the $E_{\mathrm{T} 1}$ in an HRPL is enhanced while the absence of mutation at the axial ligand, the most common strategy used to modify $E_{\mathrm{T} 1}$, supports the assumption that other structural determinants underlie the modification in laccase redox potential. $6,8,19,23$

Biochemical Characterization. Kinetic constants were assessed with the redox mediators used during screening $\left(\mathrm{K}_{4} \mathrm{Mo}(\mathrm{CN})_{8}\right.$, violuric acid, and $\left.\mathrm{ABTS}\right)$. Moreover, 2,6dimethoxy phenol (DMP, $E=0.58 \mathrm{mV}$ versus $\mathrm{NHE}$ ) was included in the measurements as a standard phenolic laccase substrate. $^{39}$ The catalytic efficiency $\left(k_{\mathrm{cat}} / K_{\mathrm{m}}\right)$ of GreeDo was higher than that of the parental OB-1 for both high-redoxpotential mediators tested, indicating that the increased $E_{\mathrm{T} 1}$ is at least partially responsible for the improved kinetics with high-redox-potential mediators (Table 1). Indeed, the enhanced kinetic constants of GreeDo for $\mathrm{K}_{4} \mathrm{Mo}(\mathrm{CN})_{8}$ were striking, with a 7.5-fold improvement in catalytic efficiency. The very high redox potential of violuric acid makes oxidation by laccase thermodynamically unfavorable, and thus, the
Table 1. Kinetic Constants ${ }^{a}$ of OB-1 and GreeDo Variants at $\mathrm{pH} 4.0$

\begin{tabular}{clll} 
substrate & kinetics constants & \multicolumn{1}{c}{ OB-1 } & \multicolumn{1}{c}{ GreeDo } \\
$\mathrm{K}_{4} \mathrm{Mo}(\mathrm{CN})_{8}$ & $K_{\mathrm{m}}(\mathrm{mM})$ & $1.02 \pm 0.11$ & $0.20 \pm 0.01$ \\
& $k_{\text {cat }}\left(\mathrm{s}^{-1}\right)$ & $143 \pm 28$ & $209 \pm 11$ \\
& $k_{\text {cat }} / K_{\mathrm{m}}\left(\mathrm{mM}^{-1} \mathrm{~s}^{-1}\right)$ & 140 & 1045 \\
violuric acid & $K_{\mathrm{m}}(\mathrm{mM})$ & $16.3 \pm 2.9$ & $18.0 \pm 4.5$ \\
& $k_{\text {cat }}\left(\mathrm{s}^{-1}\right)$ & $20.3 \pm 0.9$ & $35.1 \pm 2.6$ \\
& $k_{\text {cat }} / K_{\mathrm{m}}\left(\mathrm{mM}^{-1} \mathrm{~s}^{-1}\right)$ & 1.25 & 1.95 \\
ABTS & $K_{\mathrm{m}}(\mathrm{mM})$ & $0.014 \pm 0.001$ & $0.027 \pm 0.003$ \\
& $k_{\text {cat }}\left(\mathrm{s}^{-1}\right)$ & $455 \pm 10$ & $384 \pm 11$ \\
& $k_{\text {cat }} / K_{\mathrm{m}}\left(\mathrm{mM}^{-1} \mathrm{~s}^{-1}\right)$ & 32734 & 14222 \\
DMP & $K_{\mathrm{m}}(\mathrm{mM})$ & $0.205 \pm 0.010$ & $0.141 \pm 0.008$ \\
& $k_{\text {cat }}\left(\mathrm{s}^{-1}\right)$ & $250 \pm 5$ & $172 \pm 2$ \\
& $k_{\text {cat }} / K_{\mathrm{m}}\left(\mathrm{mM}^{-1} \mathrm{~s}^{-1}\right)$ & 1250 & 1229
\end{tabular}

${ }^{a}$ Reactions were performed in triplicate, and substrate oxidations were followed through spectrophotometric changes. To calculate the $K_{\mathrm{m}}$ and $k_{\text {cat }}$ values, the average $V_{\max }$ was represented against substrate concentration and fitted to a single rectangular hyperbolic function with SigmaPlot 10.0.

kinetic parameters are several orders of magnitude lower than those of $\mathrm{K}_{4} \mathrm{Mo}(\mathrm{CN})_{8}$. Nevertheless, GreeDo showed a 1.7-fold increased $k_{\text {cat }}$ for violuric acid, although during screening we observed a 4.8 -fold activity improvement. Leaving aside possible differences in the activity values between purified enzymes and supernatants (whose measurements can be affected by the media background, cell growth, and secretion levels), the screening assay for violuric acid was performed at $\mathrm{pH} 4.0$ over $20 \mathrm{~h}$. Hence, we suspected that these discrepancies in activity could also be explained by a higher $\mathrm{pH}$ stability at the acidic range for GreeDo (see the Biochemical Characterization section below). The $k_{\text {cat }} / K_{\mathrm{m}}$ for DMP was maintained, whereas there was a 2.3-fold drop for ABTS. This decrease probably reflects unfavorable binding of the substrate, given that the introduction of two more hydrophobic residues into the binding pocket might hinder the accommodation of the bulky ABTS molecule (see the computational analysis below).

The majority of high-redox-potential mediators are poor laccase substrates because the reaction is not thermodynamically favorable, particularly due to the differences between the redox potential of the mediator and the $\mathrm{T} 1 \mathrm{Cu}$ site. ${ }^{11,12}$ Accordingly, the activity of the GreeDo mutant on high-redoxpotential mediators was further tested by preparing several LMSs for the oxidation-decolorization-of two recalcitrant high-redox-potential dyes, reactive black 5 (RB5, $E=0.92 \mathrm{~V}$ versus NHE) and poly R-478. ${ }^{40,41}$ The general basis of the LMS is the combination of laccase with low-molecular-weight compounds which act as diffusible electron carriers; i.e., once oxidized by the laccase, they can oxidize higher-redox-potential compounds that otherwise are hardly oxidize by laccase alone. Along with $\mathrm{K}_{4} \mathrm{Mo}(\mathrm{CN})_{8}$ and violuric acid, in this experiment we included 1-hydroxybenzotriazole (HBT, $E=1.08 \mathrm{~V}$ versus NHE), another high-redox-potential mediator. The LMS formed by $\mathrm{K}_{4} \mathrm{Mo}(\mathrm{CN})_{8}$ and the GreeDo mutant gave rise to higher rates of decolorization when compared to the parental OB-1 enzyme (Figure 2A). The same effect was observed for the LMS with violuric acid and HBT, although to a lesser extent, as the laccase activity on such mediators was weaker (Figure 2B,C). Indeed, there was a strong correlation between 

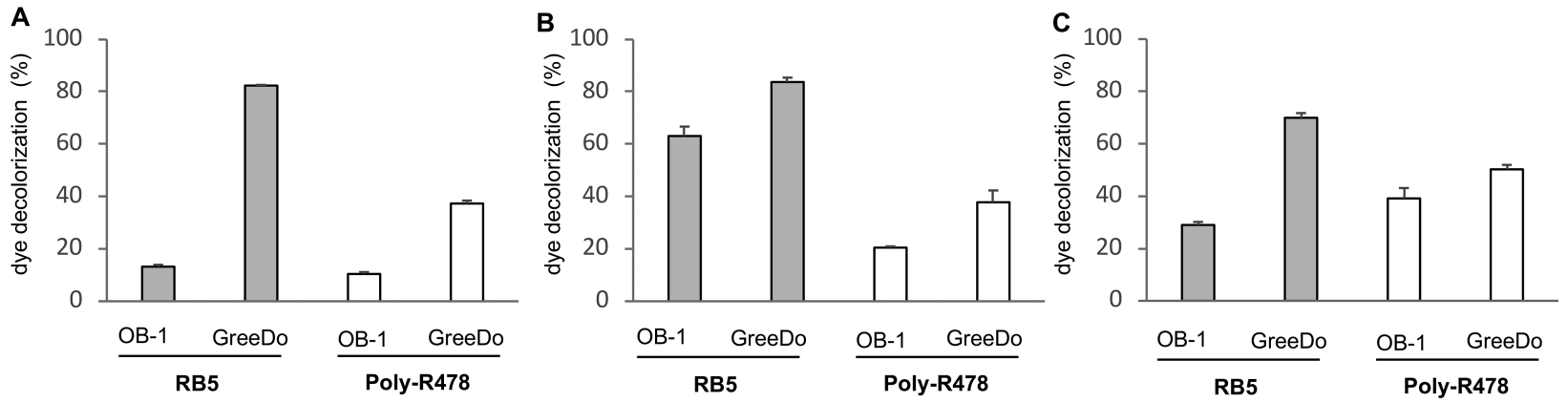

Figure 2. Dye decolorization by the LMS. The parental OB-1 and the GreeDo variant were coupled to LMS and tested for the decolorization of recalcitrant dyes. Gray bars, reactive black 5 (RB5); white bars, poly R-478. (A) LMS with $\mathrm{K}_{4} \mathrm{Mo}\left(\mathrm{CN}_{8}\right)$. (B) LMS with HBT. (C) LMS with violuric acid. Decolorization was measured after a $24 \mathrm{~h}$ incubation at room temperature in a reaction mixture containing $100 \mathrm{mM}$ sodium phosphate/citrate buffer, $\mathrm{pH} 4.0,0.16 \mu \mathrm{M}$ purified laccase (for $\mathrm{K}_{4} \mathrm{Mo}(\mathrm{CN})_{8}$ and $\mathrm{HBT}$ ) or $0.016 \mu \mathrm{M}$ laccase (for violuric acid) and the $1 \mathrm{mM}$ redox mediator. The initial dye concentrations were $0.0075 \%$ and $0.015 \%$ for RB5 and poly R-478, respectively. Decolorization was monitored at 598 and $520 \mathrm{~nm}$ for RB5 and poly R-478, respectively. Each point represents the mean and standard deviation of three independent measurements.
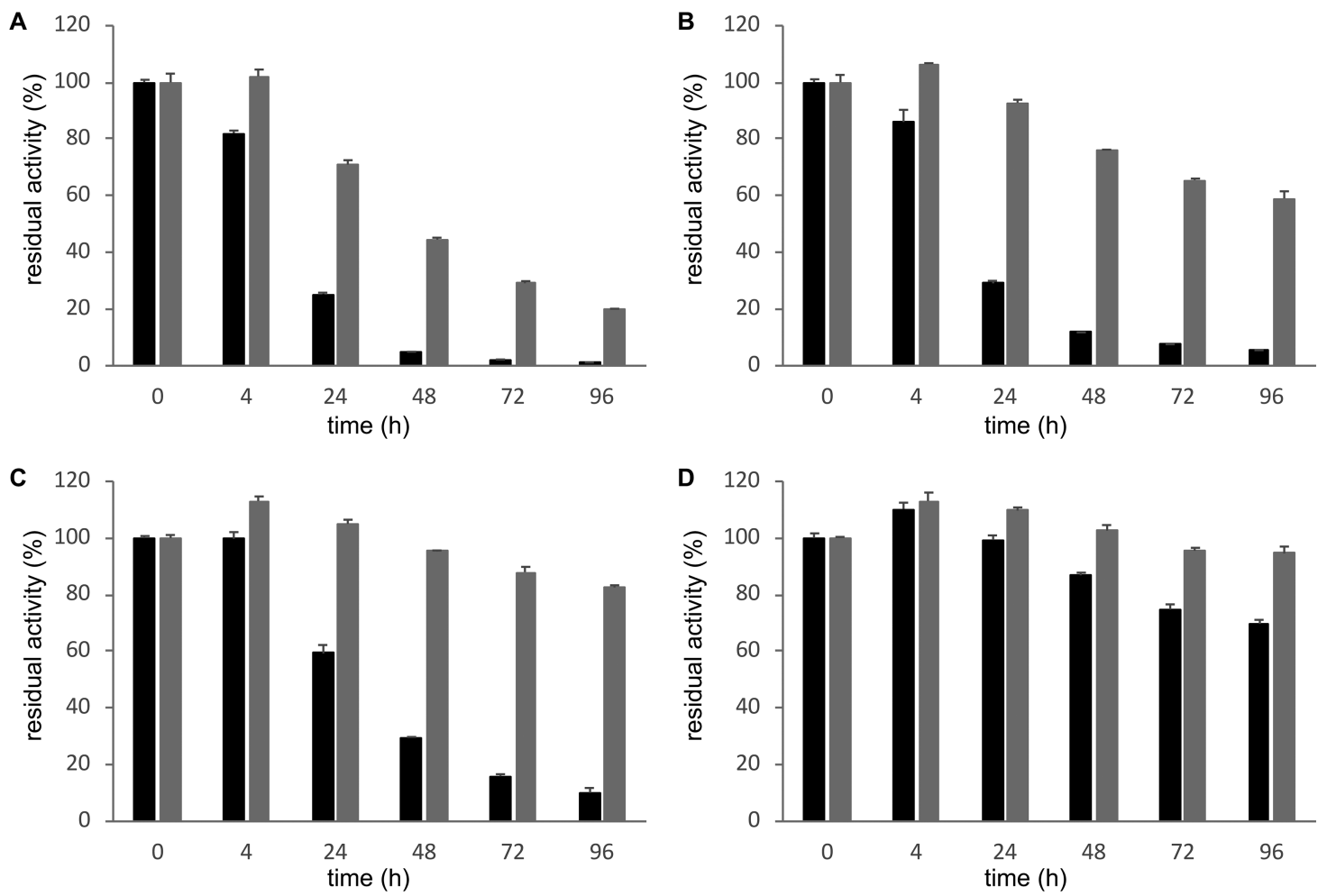

Figure 3. Acidic pH stability. The parental OB-1 (black bars) and the GreeDo variant (gray bars) were incubated for 0, 4, 24, 48, 72, and $96 \mathrm{~h}$ at different pHs: (A) $\mathrm{pH} 2$; (B) $\mathrm{pH} 3$; (C) $\mathrm{pH} 4$; (D) $\mathrm{pH}$ 5. Residual activity was measured with $3 \mathrm{mM}$ ABTS in 100 mM sodium phosphate/citrate buffer $\mathrm{pH} 4.0$, and the laccase activity was normalized to the activity at time 0 for each $\mathrm{pH}$. Each point represents the mean and standard deviation of three independent measurements.

the kinetic constants given in Table 1 and differences in the mediator's redox potential.

The kinetic thermostability of the GreeDo mutant was studied by measuring its half-life $\left(t_{1 / 2}\right)$, the time required by the enzyme to lose $50 \%$ of its initial activity at room temperature when incubated at $70{ }^{\circ} \mathrm{C}$. Unlike previous studies in which slight modifications of the laccase redox potential came at the cost of compromising stability, the enhanced $E_{\mathrm{T} 1}$ of GreeDo was accompanied with a strong increase in thermostability, with the $t_{1 / 2}$ of OB-1 increasing from 23 to $60 \mathrm{~min}$ for the GreeDo variant (Figure S7). This noticeable improvement in thermostability in an already thermostable laccase underlines the structural robustness gained through the mutations that enhanced the $E_{\mathrm{T} 1}$. The $\mathrm{pH}$ stability was measured in the $\mathrm{pH}$ range from 2.0 to 9.0. After a $96 \mathrm{~h}$ incubation at $\mathrm{pH}$ 6.0-9.0, both laccases retained their full activity, as expected at such a $\mathrm{pH}$ range (Figure S8A-D). It is well-known that the stability of fungal laccases is $\mathrm{pH}$ dependent such that they are tolerant of neutral-alkaline $\mathrm{pHs}$, but they become rapidly inactive at an acidic $\mathrm{pH}$. This is certainly an intriguing enigma, whereby fungal laccases can only work under acidic conditions in which they are quite labile, yet while they are very stable at neutral-alkaline $\mathrm{pH}$, the inhibitory effect provoked by the attachment of $\mathrm{OH}^{-}$to the $\mathrm{T} 2 / \mathrm{T} 3$ cluster inactivates them. ${ }^{42}$ When stability at acidic $\mathrm{pHs}$ was measured, the GreeDo variant retained roughly $60 \%$ of its residual activity after a $96 \mathrm{~h}$ incubation at $\mathrm{pH} 3.0$ whereas the activity of OB-1 was negligible. Indeed, the GreeDo laccase 
A

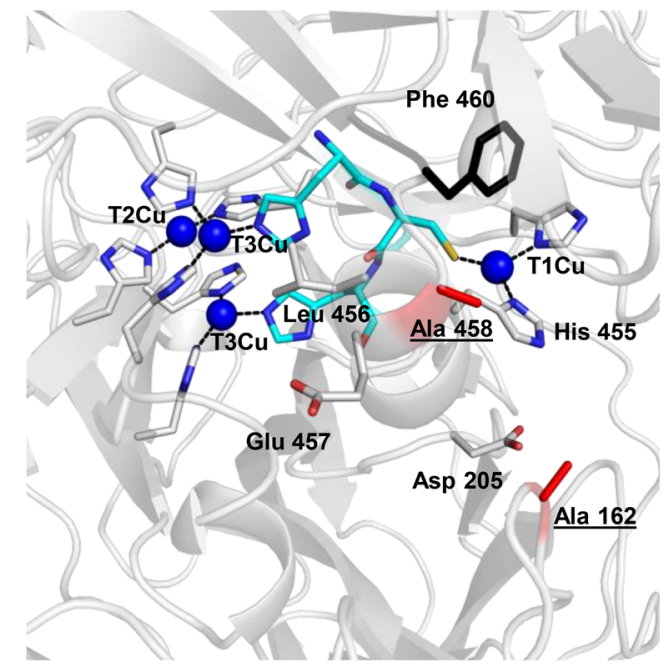

C

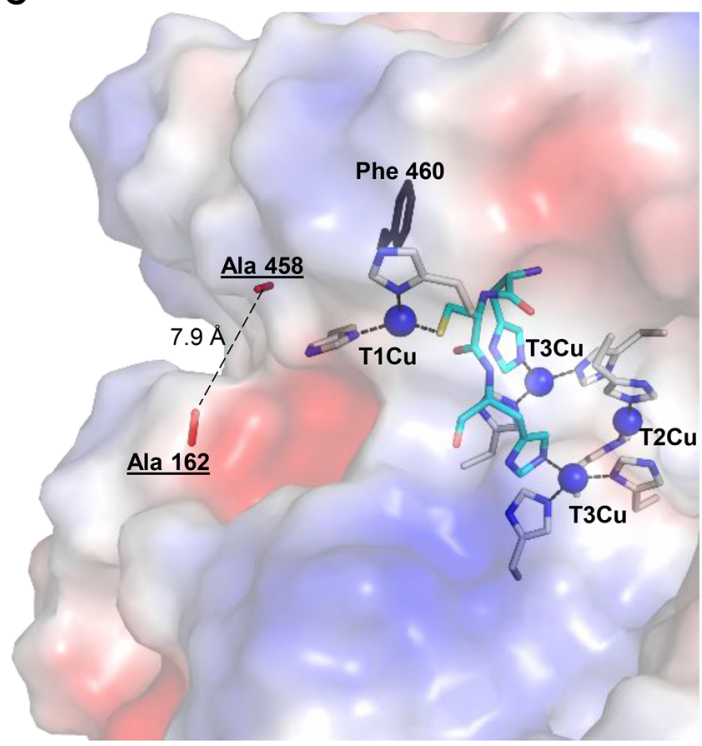

B

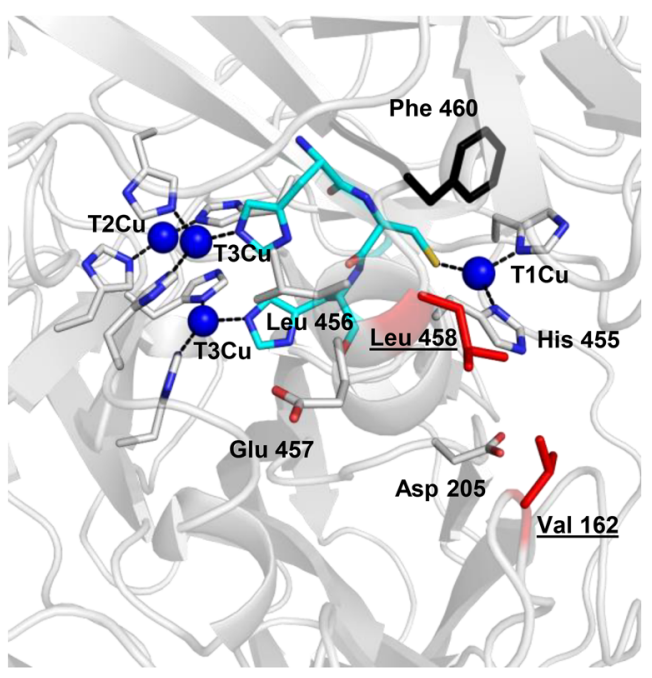

D

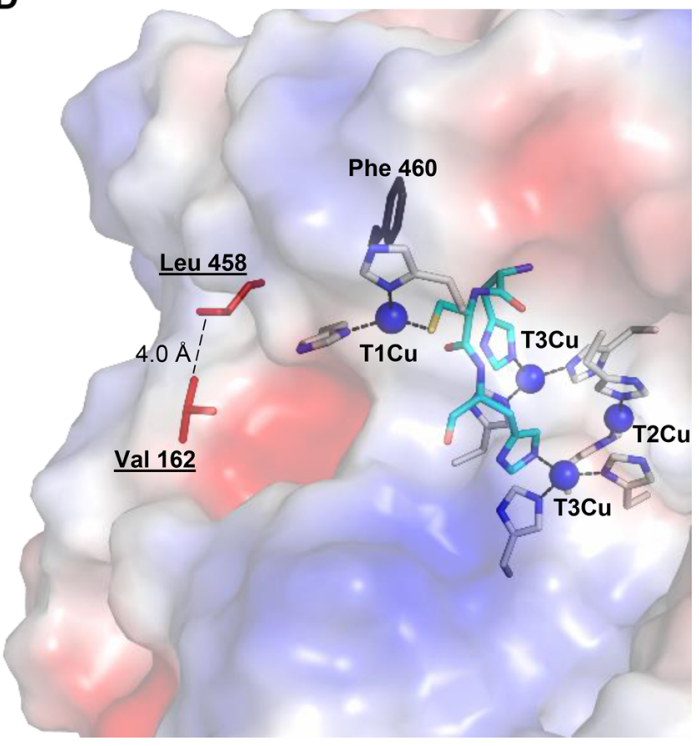

Figure 4. Location of the mutations. Representation of (A, C) the parental OB-1 and (B, D) GreeDo mutant in cartoon and surface mode. The Ala162Val and Ala458Leu mutations (depicted as red sticks) are in the vicinity of the T1Cu site closing the catalytic pocket. The surface representation highlights the shrinkage of the catalytic pocket by the hydrophobic Val162 and Leu458, reducing solvent accessibility to the nearby $\mathrm{T} 1 \mathrm{Cu}$ site. The copper atoms are shown as blue spheres and are coordinated by 10 His residues and 1 Cys, depicted as sticks. The His-Cys-His tripeptide responsible for electron transfer is highlighted in cyan, and the axial ligand Phe460 is indicated as black sticks. Asp205, Leu456, and Glu457 are highlighted in cartoon mode as sticks. The model is based on Trametes trogii laccase, PDB 2HRG (96\% sequence identity).

even conserved $\sim 20 \%$ of its activity after $96 \mathrm{~h}$ at $\mathrm{pH} 2.0$ (Figure $3 \mathrm{~A}-\mathrm{D}$ ). These values mean a roughly 11 - and 18 -fold higher tolerance of GreeDo at $\mathrm{pH} 3.0$ and 2.0, respectively, relative to OB-1. The improvement in the stability of GreeDo relative to the parental OB-1 was enhanced by the gradual increase in acidity (Figure S9) with the activity profile of the GreeDo variant slightly shifted toward acidic pH (Figure S10).

Structural and Computational Analysis. It is thought that placing the $\mathrm{T} 1 \mathrm{Cu}$ of laccase, and that of other blue copper proteins, in a more hydrophobic environment may reduce solvent accessibility, better stabilizing the less charged $\mathrm{Cu}$ (I) ion and, hence, elevating the redox potential. ${ }^{27,43,44}$ Indeed, our findings are consistent with these observations. The Ala162Val and Ala458Leu mutations of GreeDo were mapped onto the OB-1 laccase model, and both mutations were seen to be located in the vicinity of the $\mathrm{T} 1 \mathrm{Cu}$ coordination sphere, collapsing the catalytic cavity when the hydrophobicity at this site augments (Figure 4). To know whether the combination of such substitutions could be found in any other HRPL, we ran a multiple sequence alignment (MSA) using basidiomycete laccases, which addressed that, indeed, there is no natural laccase reported that brings together both Ala162 and Leu458 (Figure S11). Ala458Leu lies in the $\alpha$ helix of the highly represented Leu-Glu-Ala tripeptide of HRPLs ${ }^{6}$ (456LeuGlu-Ala458, using the PM1 laccase numbering), and the MSA indicates that this residue is also highly conserved, with only two laccases (from Antrodiella faginea ${ }^{45}$ and Cyathus bulleri ${ }^{46}$ ) also presenting Leu at this position. Conversely, the mutation Ala162Val-located in the flexible loop participating in the substrate binding cavity - is not conserved among basidiomycete laccases. It is worth noting that the PM1 wild type laccase originally harbored Val162, but in the course of evolution toward functional expression, it was substituted by Ala, together with six more mutations (His208Tyr-Ser224Gly- 
Ala239Pro-Asp281Glu-Ser426Asn-Ala461Thr) that conformed a unique mutational backbone for activity, heterologous functional expression, and stability. ${ }^{29}$ By reverting Ala162 through a stepwise mutagenesis process, the redox potential and other important biochemical characteristics were notably improved within this particular mutational context.

According to our model, the Ala162 Val and Ala458Val mutations shield the coordinating His455, reducing its exposure to the solvent (Figure 4). The side chains of Val162 and Leu458 lie close to one another, and they are orientated in such a way that they could displace any water molecules between them, which could contribute to the elevated $E_{\mathrm{T} 1}$. Moreover, enhanced hydrophobicity is proven to be important for protein stability. ${ }^{47}$ As such, it is reasonable to think that the hydrophobic shell in GreeDo is both producing an energetically favorable effect to stabilize the metal center while positively influencing temperature and $\mathrm{pH}$ stability. In this regard, rusticyanin, a member of the cupredoxin family with the highest redox potential of its clade $(680 \mathrm{mV}$ versus NHE-roughly twice that of any other cupredoxin), has a characteristic broad network of hydrophobic interactions near the copper site. The limited exposure of the copper atom to water and its extreme acid stability are derived from the stabilization and rigidity of the copper binding site. ${ }^{48}$ A similar behavior has also been shown for azurin, another cupredoxin protein, whose redox potential was increased first by enhancing hydrophobicity of the axial ligand and through hydrogen bonding. ${ }^{25}$ After that, a further enhancement of redox potential $(\sim 0.3 \mathrm{~V})$ was accomplished introducing two hydrophobic residues in the secondary coordination sphere of the $\mathrm{T} 1 \mathrm{Cu}$, which also agrees with our results. ${ }^{38}$ Although HRPLs are more complex enzymes than cupredoxins, with several redox centers and an intramolecular electron transfer pathway between them, analogous laws seem to govern their $E_{\mathrm{T} 1}$, highlighting enhanced hydrophobicity as the main driving force to increase the redox potential while conserving stability.

As mentioned above, when the difference in redox potential between the $\mathrm{T} 1 \mathrm{Cu}$ site of the laccase and the reducing substrate is larger, the catalytic efficiency is better. ${ }^{17-19}$ This is paramount in terms of expanding the laccase substrate scope, where the $E_{\mathrm{T} 1}$ may define the limits of their application. However, there are examples where low-redox-potential laccases can oxidize some low-redox-potential substrates with higher efficiency than their HRPL counterparts, suggesting that, in addition to the $E_{\mathrm{T} 1}$, binding events are also important in the overall oxidation process. ${ }^{21,22}$ To analyze the substrate binding pattern in the evolved GreeDo mutant, we turned again to the computational analysis. Alanine at positions 162 and 458 in the parental OB-1 leaves the pocket open, establishing a shallow binding site, which spreads beyond the catalytic residues. By contrast, substituting these alanines with a larger valine and leucine concentrates the pocket around His455 and Asp205, the first electron and proton acceptor, respectively. This is clearly seen when comparing the binding site pockets, as analyzed with SiteMap, for the parental OB-1 (Figure S12A) and the GreeDo mutant (Figure S12B) models. This change produces the varied effects on the different substrates studied in this work. In the case of ABTS, it hinders the formation of the most favorable binding mode in favor of a weaker one, consistent with the lower catalytic efficiency of GreeDo for this substrate. Conversely, the extended binding pocket in the parental OB-1 bound violuric acid and HBT unproductively (top docked poses with little or no spin density), the latter failing to produce catalytic contacts with His455 and Asp205. In the GreeDo mutant, the shrinkage of the pocket forces violuric acid and HBT to contact these two residues, enhancing its oxidation (Figure S12C). The improved kinetic constants for $\mathrm{K}_{4} \mathrm{Mo}(\mathrm{CN})_{8}$ oxidation were not rationalizable by the docking results since both variants displayed virtually the same binding mode, coming into close contact with His455 and nearby Asp205. However, further analysis by molecular dynamics simulations indicated that the root-mean-square deviation (RMSD) distribution is more favorable for the GreeDo mutant, which forms more reactive contacts with this redox mediator (Figure S13).

Together, these results highlight how both the $E_{\mathrm{T} 1}$ and the features controlling substrate binding should be taken into account when assessing the catalytic performance of laccases. Moreover, hydrophobicity in the proximity of the $\mathrm{T} 1 \mathrm{Cu}$ can exert beneficial effects on distinct enzymatic properties: redox potential, catalytic performance for high-redox-potential mediators, acidic $\mathrm{pH}$ stability, and kinetic thermostability.

\section{CONCLUSIONS AND OUTLOOK}

By oxidizing a wide range of high-redox-potential substrates, harnessing redox mediators to expand their substrate scope, or simply just transferring electrons directly from cathodic compartments, HRPLs emerge as true "wildcard biocatalysts" for dozens of biotechnological applications. Here, we have combined computational methods and directed evolution for the first time to design an HRPL variant with elevated $E_{\mathrm{T} 1}$, strong activity for high-redox-potential mediators, and improved stability in terms of temperature and $\mathrm{pH}$. Understanding precisely how $E_{\mathrm{T} 1}$ is regulated and why it varies significantly among structurally similar laccases still remains a challenge. Nevertheless, our findings point to the hydrophobic environment of $\mathrm{T} 1 \mathrm{Cu}$ as one of the major structural determinants in modulating redox potential in fungal laccases. Accordingly, further engineering efforts should focus on this region to better understand modulations of redox potential over a wider range. We hypothesize that introducing an even more extensive hydrophobic network in the surroundings of the $\mathrm{T} 1 \mathrm{Cu}$ site could raise the redox potential, yet special attention should be paid to not fully enclose the catalytic pocket as substrate binding could otherwise be impeded. Conversely, accessibility to the $\mathrm{T} 1 \mathrm{Cu}$ site is not crucial from an electrochemical point of view since an HRPL properly connected to a cathodic compartment can accept electrons in a direct manner.

Considering all the improved properties, where an increase in the redox potential along with an enhancement in the activity for the high-redox-potential mediator stands out, this highly stable evolved HRPL could represent a suitable candidate to be used in future LMS programs (including bioremediation, pulp-biobleaching, and other harsh industrial processes) as well as biodevice engineering applications (biosensors and biofuel cells). Finally, the present study highlights the potential of combining in silico and experimental enzyme evolution. In particular, current modeling techniques seem mature enough to quickly provide specific regions of the enzyme where to focus more robust experimental evolution techniques. 


\section{MATERIAL AND METHODS}

Materials. The expression shuttle vector pJRoC30 containing a uracil auxotrophy and ampicillin marker for selection came from California Institute of Technology (CALTECH). The yeast transformation kit, ABTS $\left(2,2^{\prime}\right.$ azino-bis(3-ethylbenzothiazoline-6-sulfonic acid)), DMP (2, 6dimethoxyphenol), violuric acid, HBT (1-hydroxybenzotriazole), $\mathrm{K}_{4} \mathrm{Mo}(\mathrm{CN})_{8}$, reactive black 5, poly $\mathrm{R}-478$, Antifoam 204, and Taq DNA polymerase were from Sigma-Aldrich/ Merck (Darmstadt, Germany). The PfuUltra was purchased from Agilent. Saccharomyces cerevisiae BJ5465 was acquired from LGC Promochem (Barcelona, Spain). Escherichia coli XL2-Blue was purchased from Stratagene (La Jolla, CA). PTM1 trace salts, Zeocin, Pichia pastoris strain X-33, and its expression vector pPICZ B were from Invitrogen (Carlsbad, CA). The Zymoprep yeast plasmid miniprep kit and Zymoclean Gel DNA recovery kit were from Zymo Research (Orange, CA). The NucleoSpin Plasmid kit was purchased from Macherey-Nagel (Düren, Germany). The restriction enzymes (BamHI, XhoI, BstI, XbaI, SacI), the Antarctic phosphatase, and the DNA ligation kit were bought from New England Biolabs (Hertfordshire, UK). Culture media was prepared with the ingredients and recipes described elsewhere. $^{49}$

Laboratory Evolution. The parent OB-1 was obtained as described elsewhere. ${ }^{29}$ All PCR products were loaded onto a preparative agarose gel and purified by use of the Zymoclean Gel DNA recovery kit. The recovered DNA fragments were cloned under the control of the GAL1 promoter of the pJRoC30 expression shuttle vector, with use of BamHI and XhoI to linearize the plasmid and to remove the parent gene. The linearized vector was loaded onto a preparative agarose gel and purified with the Zymoclean Gel DNA recovery kit.

Error-Prone $P C R$ (epPCR). The whole parental type gene was subjected to epPCR with (i) Taq DNA polymerase in the presence of $\mathrm{MnCl}_{2}$ (mutational load: $1-3$ mutations/Kb); (ii) Mutazyme II with low mutational frequencies-M1-(0-4.5 mutations $/ \mathrm{Kb})$ and Mutazyme II with high mutational frequencies-M2-(4.5-9 mutations/Kb). (i) Mutagenic PCR was prepared in a final volume of $50 \mu \mathrm{L}$ containing $3 \%$ DMSO, $90 \mathrm{nM}$ sense (5'-CCTCTATACTTTAACGTCAAGG-3') and RMLC antisense (5'-GCTTACATTCACGCCCTCCC-3'), $0.3 \mathrm{mM}$ dNTPs (0.075 mM each), $0.01 \mathrm{mM}$ $\mathrm{MnCl}_{2}, 0.1 \mathrm{ng} / \mu \mathrm{L}$ template, $1.5 \mathrm{mM} \mathrm{MgCl}$, and $0.05 \mathrm{U} / \mu \mathrm{L}$ Taq DNA polymerase. (ii) Mutagenic PCR was prepared in a final volume of $50 \mu \mathrm{L}$ containing $1 \mathrm{X}$ buffer Mutazyme II $(10 \times)$, 3\% DMSO, $370 \mathrm{nM}$ sense (5'-CCTCTATACTTTAACGTCAAGG-3') and RMLC antisense ( $5^{\prime}$-GCTTACATTCACGCCCTCCC-3'), $0.8 \mathrm{mM}$ dNTPs (0.200 mM each), $40 \mathrm{ng} / \mu \mathrm{L}$ template, and $0.05 \mathrm{U} / \mu \mathrm{L}$ Mutazyme II polymerase. epPCRs were performed on a gradient thermocycler (Mycycler, BioRad) using the following parameters: 95 ${ }^{\circ} \mathrm{C}$ for $2 \mathrm{~min}(1 \mathrm{cycle}) ; 94{ }^{\circ} \mathrm{C}$ for $45 \mathrm{~s}, 50{ }^{\circ} \mathrm{C}$ for $30 \mathrm{~s}, 72{ }^{\circ} \mathrm{C}$ for $90 \mathrm{~s}$ (30 cycles in the case of $\mathrm{Taq}$ polymerase and Mutazyme II with high mutational frequencies, 20 cycles in the case of Mutazyme II with low mutational frequencies); and 72 ${ }^{\circ} \mathrm{C}$ for $10 \mathrm{~min}$ ( $\left.1 \mathrm{cycle}\right)$. A $200 \mathrm{ng}$ portion of epPCR product was mixed with $100 \mathrm{ng}$ of the linearized vector and transformed into $S$. cerevisiae competent cells using the yeast transformation kit. Inserts and linearized plasmid shared $40 \mathrm{bp}$ of homology to allow recombination and the in vivo cloning by the yeast. Transformed cells were plated on SC drop-out plates being incubated for 3 days at $30{ }^{\circ} \mathrm{C}$. A total of 2400 clones were screened (1000 clones for Taq/ $\mathrm{MnCl}_{2}, 1000$ clones for the M1 library, and 400 clones for the M2 library).

Combinatorial Saturation Mutagenesis (Ala162, Ala458). Three PCR reactions were carried out in a final volume of 50 $\mu \mathrm{L}$ containing $3 \%$ DMSO, $0.3 \mathrm{mM}$ dNTPs ( $0.075 \mathrm{mM}$ each), $0.05 \mathrm{U} / \mu \mathrm{L}$ PfuUltra DNA polymerase, and $2 \mathrm{ng} / \mu \mathrm{L}$ template, but each of them with different primers. For PCR 1, $0.25 \mu \mathrm{M}$ RMLN was used as forward primer and three reversed primers in the same reaction with concentrations according to the protocol of Kille and co-workers: ${ }^{50}$ (i) AHN162R (5'TTGATGCTGCGACCGAGGCCGTTGATAAGAGTAGCATCGGCAGTCGGAHNCGCCGGGCCGACTT-3'), (ii) CDB162R 5'-TTGATGCTGCGACCGAGGCCGTTGATAAGAGTAGCATCGGCAGTCGGCDBCGCCGGGCCGACTT-3'), and (iii) CCA162R (5'-TTGATGCTGCGACCGAGGCCGTTGATAAGAGTAGCATCGGCAGTCGGCCACGCCGGGCCGACTT-3'). For PCR 2, $0.25 \mu \mathrm{M}$ of CZF was used as forward primer ( $5^{\prime}$-GATGCTACTCTTATCAACGGCCTCGGTCGCAGCATCAA-3') and $0.25 \mu \mathrm{M}$ of CZR as reverse primer (5'-GGAAGTCGATGTGGCAGTGGAGGAACCACGGGCCGGGG-3'). For PCR 3, three forward primers were used in same reaction with concentrations according to Kille at al.: ${ }^{50}$ (i) NDT458F (5'-CCCCGGCCCGTGGTTCCTCCACTGCCACATCGACTTCCACCTTGAGNDTGGGTTCACGGTCGTC-3'), (ii) VHG458F (5'-CCCCGGCCCGTGGTTCCTCCACTGCCACATCGACTTCCACCTTGAGVHGGGGTTCACGGTCGTC$\left.3^{\prime}\right)$, and (iii) TGG458F (5'-CCCCGGCCCGTGGTTCСTCCACTGCCACATCGACTTCCACCTTGAGTGGGGGTTCACGGTCGTC-3') and $0.25 \mu \mathrm{M}$ RMLC as reverse primer. Codon substitutions, where $\mathrm{N}=\mathrm{A} / \mathrm{T} / \mathrm{C} / \mathrm{G}, \mathrm{D}=$ no $\mathrm{C}$, $\mathrm{H}=$ no $\mathrm{G}, \mathrm{B}=$ no $\mathrm{A}$, and $\mathrm{V}=$ no $\mathrm{T}$, are shown in italics. PCR reactions were performed using the following program: $95{ }^{\circ} \mathrm{C}$ for 2 min $(1$ cycle $) ; 95{ }^{\circ} \mathrm{C}$ for $45 \mathrm{~s}, 50{ }^{\circ} \mathrm{C}$ for $45 \mathrm{~s}$, and $72{ }^{\circ} \mathrm{C}$ for $60 \mathrm{~s}$ ( 28 cycles); and $72{ }^{\circ} \mathrm{C}$ for $10 \mathrm{~min}$ ( 1 cycle). PCR products were transformed together with linearized plasmid into yeast by IVOE, ${ }^{51}$ and 1550 clones were screened.

Saturation Mutagenesis at Pro160 and Ile452. Saturation mutagenesis was carried out using degenerated NNS codons ( $\mathrm{N}=\mathrm{A} / \mathrm{T} / \mathrm{C} / \mathrm{G} ; \mathrm{S}=\mathrm{G} / \mathrm{C})$, creating two libraries. For library P160, $50 \mu \mathrm{L}$ was used containing 3\% DMSO, $0.3 \mathrm{mM}$ dNTPs (0.075 mM each), $0.05 \mathrm{U} / \mu \mathrm{L}$ PfuUltra DNA polymerase, and $2 \mathrm{ng} / \mu \mathrm{L}$ template (GreeDo) with $0.25 \mu \mathrm{M}$ RMLN and 0.25 $\mu \mathrm{M}$ P160-R (5'-ATCGGCAGTCGGTACCGCSNNGCCGACTTTGGCAGCCAAGTG-3') or $0.25 \mu \mathrm{M}$ RMLC and P160F (5'-CACTTGGCTGCCAAAGTCGGCNNSGCGGTACCGACTGCCGAT-3'). For library I452, $50 \mu \mathrm{L}$ was used containing 3\% DMSO, $0.3 \mathrm{mM}$ dNTPs ( $0.075 \mathrm{mM}$ each), 0.05 $\mathrm{U} / \mu \mathrm{L}$ PfuUltra DNA polymerase, and $2 \mathrm{ng} / \mu \mathrm{L}$ template (GreeDo) with $0.25 \mu \mathrm{M}$ RMLN and $0.25 \mu \mathrm{M}$ of I452-R (5'GTGAACCCTAACTCAAGGTGGAAGTCSNNGTGGCAGTGGAGGAACC-3') or $0.25 \mu \mathrm{M}$ RMLC and I452-F ( $5^{\prime}$ GGTTCCTCCACTGCCACNNSGACTTCCACCTTGAGTTAGGGTTCAC-3'). PCR reactions were performed as follows: $95{ }^{\circ} \mathrm{C}$ for $2 \mathrm{~min}(1 \mathrm{cycle})$; $95^{\circ} \mathrm{C}$ for $45 \mathrm{~s}, 50{ }^{\circ} \mathrm{C}$ for 45 s, and $72{ }^{\circ} \mathrm{C}$ for $60 \mathrm{~s}$ ( 28 cycles); and $72{ }^{\circ} \mathrm{C}$ for $10 \mathrm{~min}(1$ cycle). PCR products were transformed together with linearized plasmid into yeast by IVOE. ${ }^{51}$ For each library, 500 clones were screened.

Focused Evolution at the Leu383-Thr461 Segment. The region between Leu383-Thr461 was subjected to MORPHING (mutagenic organized recombination process by homol- 
ogous in vivo grouping). ${ }^{32}$ Mutagenic PCR was prepared in a final volume of $50 \mu \mathrm{L}$ containing $3 \%$ DMSO, $90 \mathrm{nM}$ GreeDoepPCR-F (5'-CCTCTGGAAGTGTATACTCGCTCCC-3'), $90 \mathrm{nM}$ 9C1-epPCR-R (5'-GGGACCGGGTTCGTAGCGGCGACGTC-3'), $0.3 \mathrm{mM}$ dNTPs (0.075 mM each), $0.1 \mathrm{MnCl}_{2}$, $1.5 \mathrm{mM} \mathrm{MgCl}{ }_{2}, 0.05 \mathrm{U} / \mu \mathrm{L}$ Taq DNA polymerase, and $1 \mathrm{ng} /$ $\mu \mathrm{L}$ template. The amplification parameters were $94{ }^{\circ} \mathrm{C}$ for 2 $\min \left(1\right.$ cycle); $94{ }^{\circ} \mathrm{C}$ for $45 \mathrm{~s}, 50{ }^{\circ} \mathrm{C}$ for $30 \mathrm{~s}$, and $72{ }^{\circ} \mathrm{C}$ for 90 $\mathrm{s}(28$ cycles $)$; and $72{ }^{\circ} \mathrm{C}$ for $10 \mathrm{~min}$ ( 1 cycle). The remaining portions of the whole GreeDo gene were amplified by highfidelity PCR in a final volume of $50 \mu \mathrm{L}$ containing $3 \% \mathrm{DMSO}$, $0.5 \mu \mathrm{M}$ HF9C1-F (5'-GTCGTCATGGCCGAGGACATTCCC-3'), and $0.5 \mu \mathrm{M}$ RMLC or $0.5 \mu \mathrm{M}$ HF9C1-R (5'GGAGATCTCAATGTCCGCGTTCGCA-3') for the other high-fidelity fragment, $1 \mathrm{mM}$ dNTPs $(0.25 \mathrm{mM}$ each), $0.05 \mathrm{U} /$ $\mu \mathrm{L}$ PfuUltra DNA polymerase, and $2 \mathrm{ng} / \mu \mathrm{L}$ template. Highfidelity PCR was carried out with the following program: $95^{\circ} \mathrm{C}$ for $2 \mathrm{~min}(1 \mathrm{cycle}) ; 95{ }^{\circ} \mathrm{C}$ for $45 \mathrm{~s}, 50{ }^{\circ} \mathrm{C}$ for $30 \mathrm{~s}$, and $72{ }^{\circ} \mathrm{C}$ for $90 \mathrm{~s}$ ( 28 cycles); and $72{ }^{\circ} \mathrm{C}$ for $10 \mathrm{~min}$ ( 1 cycle). PCR products were transformed together with linearized plasmid into yeast by IVOE, ${ }^{51}$ and 1000 clones were screened.

High-Throughput Screening. Individual clones were picked and inoculated in sterile 96-well plates (Greiner Bio-One, $\mathrm{GmbH}$ ), referred to as master plates, containing $200 \mathrm{~mL}$ of SEM per well. In each plate, column number 6 was inoculated with the parent type, and one well (H1-control) was inoculated with S. cerevisiae transformed with pJRoC30-MtL plasmid (laccase without activity). Plates were sealed with Parafilm to prevent evaporation and incubated at $30{ }^{\circ} \mathrm{C}, 220$ $\mathrm{rpm}$, and $80 \%$ relative humidity in a humidity shaker (Minitron, Infors) for 5 days. The master plates were centrifuged (Eppendorf 5810R centrifuge) for $10 \mathrm{~min}$ at $2500 \mathrm{~g}$ and $4{ }^{\circ} \mathrm{C}$. Aliquots of the supernatants $(20 \mu \mathrm{L})$ were transferred from the master plates to three replica plates with the aid of a liquid handler robotic station Freedom EVO (Tecan). A $180 \mu \mathrm{L}$ portion of a corresponding reaction mixture $[100 \mathrm{mM}$ sodium phosphate/citrate buffer $\mathrm{pH} 4.0$ (3 $\mathrm{mM} \mathrm{ABTS}$ or $2 \mathrm{mM} \mathrm{K} \mathrm{K}_{4} \mathrm{Mo}(\mathrm{CN})_{8}$ or $20 \mathrm{mM}$ violuric acid)] was added to each plate with the help of a pipetting robot (Multidrop Combi Reagent Dispenser, Thermo Scientific). The plates were briefly stirred and absorbance was measured at $418 \mathrm{~nm}$ for ABTS $\left(\varepsilon_{\mathrm{ABTS}}{ }^{\bullet+}=36000 \mathrm{M}^{-1} \mathrm{~cm}^{-1}\right)$, at $388 \mathrm{~nm}$ for $\mathrm{K}_{4} \mathrm{Mo}(\mathrm{CN})_{8}\left(\varepsilon_{\mathrm{K}_{4} \mathrm{Mo}(\mathrm{CN})_{8}}=1460 \mathrm{M}^{-1} \mathrm{~cm}^{-1}\right)$, and at $515 \mathrm{~nm}$ for violuric acid $\left(\varepsilon=98 \mathrm{M}^{-1} \mathrm{~cm}^{-1}\right)$. The ABTS measurement was performed in kinetic mode, while $\mathrm{K}_{4} \mathrm{Mo}(\mathrm{CN})_{8}$ and violuric acid were in end point mode with a plate reader (SPECTRAMax Plus 384, Molecular Devices). The values were normalized against the parent type of the corresponding plate, and selected variants came from the activity improvements for $\mathrm{K}_{4} \mathrm{Mo}(\mathrm{CN})_{8}$ and violuric acid. To rule out the selection of false positives, two rescreenings were carried out as described elsewhere. ${ }^{29}$

DNA Sequencing. Laccase genes were sequenced by GATC-Biotech. The primers used were RMLN, PM1FS ( $5^{\prime}-$ ACGACTTCCAGGTCCCTGACCAAGC- $\left.3^{\prime}\right)$, PM1RS (5'TCAATGTCCGCGTTCGCAGGGA-3'), and RMLC.

Biochemical Characterization. The production and purification were adapted from previous protocols with minor modifications. ${ }^{52,53}$ ABTS, DMP, $\mathrm{K}_{4} \mathrm{Mo}(\mathrm{CN})_{8}$, and violuric acid kinetic constants for laccase variants were estimated in sodium phosphate/citrate buffer ( $\mathrm{pH}$ 4.0, 100 $\mathrm{mM}$ ). Reactions were performed in triplicate, and substrate oxidations were followed through spectrophotometric changes $\left(\varepsilon_{418}(\mathrm{ABTS})^{\bullet+}=36000 \mathrm{M}^{-1} \mathrm{~cm}^{-1} ; \varepsilon_{469}(\mathrm{DMP})=27500 \mathrm{M}^{-1}\right.$ $\mathrm{cm}^{-1} ; \varepsilon_{388}\left(\mathrm{~K}_{4} \mathrm{Mo}(\mathrm{CN})_{8}\right)=1460 \mathrm{M}^{-1} \mathrm{~cm}^{-1} ; \varepsilon_{515}$ (violuric acid) $\left.=98 \mathrm{M}^{-1} \mathrm{~cm}^{-1}\right)$. To calculate the $K_{\mathrm{m}}$ and $k_{\text {cat }}$ values, the average $V_{\max }$ was represented against substrate concentration and fitted to a single rectangular hyperbolic function with SigmaPlot 10.0. Kinetic thermostability and $\mathrm{pH}$ stability were performed as reported previously. ${ }^{49}$

Spectroelectrochemical Characterization. All spectroelectrochemical characterization was performed with enzymes produced in $P$. pastoris.

Enzyme Preparation. Laccase variants produced in $S$. cerevisiae do not yield a sufficient amount of protein required for spectroelectrochemical studies. We turned to Pichia pastoris as an alternative host due to its ability to grow at very high cell densities under the control of strong promoters and to secrete high amounts of protein while maintaining similar biochemical properties. ${ }^{52}$ Both OB-1 and GreeDo variants were cloned in $P$. pastoris under the inducible PAOX1 promoter, produced in the MBR $7 \mathrm{~L}$ bioreactor, and purified to homogeneity as reported previously. ${ }^{52}$

Electrode Preparation. Two types of working electrodes were used in this study, viz. graphite electrodes (GEs) from Alfa Aesar (Ward Hill, MA) with a geometrical area of 0.073 $\mathrm{cm}^{2}$ and a homemade capillary gold electrode (vide inf $\mathrm{ra}$ ). GEs were polished on a silicon carbide grinding paper (Grit 1000/P 2500, Buehler), rinsed thoroughly with Milli-Q $\mathrm{H}_{2} \mathrm{O}$, and let dry. For biomodification, $10 \mu \mathrm{L}$ of either OB-1 or GreeDo solution was dropped onto the GE surface and allowed to adsorb for $20 \mathrm{~min}$.

Open-Circuit Potential Measurements. Open-circuit potentials of biomodified electrodes were measured using a $\mu$ Autolab Type III/FRA2 potentiostat/galvanostat from Metrohm Autolab B. V. (Utrecht, The Netherlands) in an electrochemical cell with a total volume of $40 \mathrm{~mL}$ thermostated at $25{ }^{\circ} \mathrm{C}$. AglAgCl|sat. $\mathrm{KCl}(0.199 \mathrm{~V}$ versus $\mathrm{NHE})$ was used as a reference electrode and biomodified graphite electrode as a working electrode. The experiments were carried out in $\mathrm{O}_{2}$ saturated $0.1 \mathrm{M}$ phosphate buffer $\mathrm{pH}$ 6.0.

Redox Titration. The redox potential of the $\mathrm{T} 1$ site of laccases was defined by mediated spectroelectrochemical redox titration according to the procedure reported earlier. ${ }^{33,34}$ The home-built spectroelectrochemical cell consisted of a $1 \mathrm{~cm}$ long capillary Au electrode with an inner diameter of $350 \mu \mathrm{m}$, operating both as the working electrode and as a cuvette with a total volume of just $1 \mu \mathrm{L}$. The input and output optical fibers (FCB-UV 400/050-2 and FCUV 200, respectively) were obtained from Ocean Optics (Dunedin, FL) and attached to the ends of the capillary. The system comprised a DH-2000 light source and an HR4000CG-UV-NIR spectrometer from Ocean Optics. The spectra were recorded with Ocean Optics Spectra Suite software. The potential of the Au capillary electrode was controlled using a three-electrode potentiostat (Zata Electronics, Lund, Sweden). A platinum wire was used as a counter electrode, and a $\mathrm{Ag} \mid \mathrm{AgCll} 3 \mathrm{M} \mathrm{NaCl}$ electrode, separated from the enzyme solution by two ceramic frits and a buffer solution salt bridge, served as a reference electrode. The working capillary Au electrode was cleaned for ca. $24 \mathrm{~h}$ in freshly prepared piranha solution (3:1 (v:v) 96\% sulfuric acid:30\% hydrogen peroxide solution). For improvement of the electrochemical communication between the electrode and the enzyme molecules, the reduced forms of three redox mediators, $\mathrm{K}_{4}\left[\mathrm{Fe}(\mathrm{CN})_{6}\right], \mathrm{K}_{4}\left[\mathrm{~W}(\mathrm{CN})_{8}\right]$, and $\mathrm{K}_{4}\left[\mathrm{Mo}(\mathrm{CN})_{8}\right]$, 
were used. The final concentration of each mediator in the cell was $2 \mathrm{mM}$, and their midpoint redox potentials were 0.43 , 0.52 , and $0.78 \mathrm{~V}$ versus $\mathrm{NHE}^{.54}$ All the reported potentials in this work are given versus NHE.

Modeling and Computer-Aided Evolution. The OB-1 model was built with Schrodinger homology modeling software, using PDB 2HRG (96\% sequence identity) as a template. ${ }^{55,56}$ Protonation states of titratable residues were optimized with PROPKA simulating $\mathrm{pH} 4.0$ (experimental conditions) and double-checked with the $\mathrm{H}++$ server. $^{57,58}$ The $\mathrm{T} 1$ pocket was characterized with SiteMap, and violuric acid was docked with Glide SP. ${ }^{59,60}$ To do so, substrate electrostatic potential (ESP) charges were obtained optimizing its geometry at the M06/6-31G* level of theory, modeling the solvent with the Poisson-Boltzmann model, using Jaguar. ${ }^{61}$ The five most favorable poses of the OB-1/substrate complex were scored with quantum mechanics/molecular mechanics (QM/MM) spin density calculations, a theoretical tool that proved its utility in laccases' reactivity rationalization and design. ${ }^{21,62,63}$ The conformation that, among those that display catalytic contacts with His455 and Asp205, had the highest substrate spin density was selected for enzyme evolution.

OB-1 redesign was carried out with PELE. ${ }^{64,65}$ Importantly, violuric acid was modeled in its oxidized state, aiming at pushing the electron transfer driving force by stabilizing the substrate binding after losing one electron. Every residue within 10 Å of the substrate was mutated, one by one, to all the possible remaining 19 amino acids. For each enzyme variant, the substrate was perturbed with $0.5 \AA$ translations and 0.1 radians rotations while the protein backbone was subjected to small anisotropic network model (ANM) displacements. The simulation of each mutant (and the reference OB-1) lasted $1 \mathrm{~h}$, accumulating 30 Monte Carlo steps. The enzyme-substrate interaction energy was then used to score each mutant. A residue position was considered to be promising if at least two mutations led to a decrease in interaction energy greater than 3 $\mathrm{kcal} / \mathrm{mol}$ (compared to the results from the reference OB-1). Such a severe threshold was intended to select only a few positions for further analysis.

Analysis of Mediator Binding Mode. The GreeDo mutant was built and refined (side chain repacking) on top of the OB1 model with Prime, and the T1 cavities of both enzymes were characterized with SiteMap. ${ }^{55,60}$ The detected pockets were then used to dock VA, HBT, $\mathrm{K}_{4} \mathrm{Mo}(\mathrm{CN})_{8}$, and $\mathrm{ABTS}$ with Glide SP. ${ }^{59}$ Ligand charges were obtained as mentioned above. The five most favorable poses were scored with QM/MM spin density calculations. ${ }^{21}$

Molecular Dynamics Analysis. The parental $/ \mathrm{K}_{4} \mathrm{Mo}(\mathrm{CN})_{8}$ and GreenDo/ $\mathrm{K}_{4} \mathrm{Mo}(\mathrm{CN})_{8}$ systems were solvated with a $10 \AA$ buffer of waters in an orthorhombic box, neutralized, and 0.15 $\mathrm{M} \mathrm{NaCl}$ was added. After equilibration (default settings), $20 \times$ $3 \mathrm{~ns}$ production runs were performed with Desmond at $300 \mathrm{~K}$. The OPLS-2005 force-field and the SPC explicit water model were used. $^{66,67}$ The temperature was regulated with the NoséHoover chain thermostat with a relaxation time of $1.0 \mathrm{ps}$, and the pressure was controlled with the Martyna-Tobias-Klein barostat with isotropic coupling and a relaxation time of 2.0 ps. $^{68,69}$ The RESPA integrator was employed with bonded, near, and far time steps of $2.0,2.0$, and $6.0 \mathrm{fs}$, respectively. ${ }^{70} \mathrm{~A}$ $9 \AA$ cutoff was used for non-bonded interactions together with the smooth particle mesh Ewald method. ${ }^{71}$

\section{ASSOCIATED CONTENT}

\section{Supporting Information}

The Supporting Information is available free of charge on the ACS Publications website at DOI: 10.1021/acscatal.9b00531.

Additional data and figures including structures, UV-vis spectrum, linearity of the $\mathrm{K}_{4} \mathrm{Mo}(\mathrm{CN})_{8}$ assay, determination of the coefficient of variance, schematics, relative activity vs number of clones, potentiograms, residual activity vs time, improvement in residual activity, $\mathrm{pH}$ activity profile, and molecular dynamics simulations (PDF)

\section{AUTHOR INFORMATION}

\section{Corresponding Authors}

*E-mail: victor.guallar@bsc.es.

*E-mail: malcalde@icp.csic.es.

ORCID

Roland Ludwig: 0000-0002-5058-5874

Miguel Alcalde: 0000-0001-6780-7616

Notes

The authors declare no competing financial interest.

\section{ACKNOWLEDGMENTS}

We thank Dr. Roman Kittl and Florian Csarman (University of Natural Resources and Life Science, Vienna) for assisting in Pichia pastoris fermentations. This work was supported by the European Union project Bioenergy-FP7-PEOPLE-2013-ITN607793, the COST Action [CM1303 Systems Biocatalysis], the Swedish Energy Agency (44707-1), the Knowledge Foundation (20170168), and the Spanish Government [BIO2016-79106-R-Lignolution and CTQ2016-79138-R].

\section{REFERENCES}

(1) Alcalde, M. Laccases: Biological Functions, Molecular Structure and Industrial Applications. In Industrial Enzymes; Springer: New York, 2007; pp 461-476.

(2) Mate, D. M.; Alcalde, M. Laccase Engineering: From Rational Design to Directed Evolution. Biotechnol. Adv. 2015, 33, 25-40.

(3) Gianfreda, L.; Xu, F.; Bollag, J.-M. Laccases: a Useful Group of Oxidoreductive Enzymes. Biorem. J. 1999, 3, 1-26.

(4) Shleev, S.; Jarosz-Wilkolazka, A.; Khalunina, A.; Morozova, O.; Yaropolov, A.; Ruzgas, T.; Gorton, L. Direct Electron Transfer Reactions of Laccases from Different Origins on Carbon Electrodes. Bioelectrochemistry 2005, 67, 115-124.

(5) Baldrian, P. Fungal Laccases - Occurrence and Properties. FEMS Microbiol. Rev. 2006, 30, 215-242.

(6) Xu, F.; Berka, R. M.; Wahleithner, J. A.; Nelson, B. A.; Shuster, J. R.; Brown, S. H.; Palmer, A. E.; Solomon, E. I. Site-directed Mutations in Fungal Laccase: Effect on Redox Potential, Activity and pH Profile. Biochem. J. 1998, 334, 63.

(7) Palmer, A. E.; Randall, D. W.; Xu, F.; Solomon, E. I. Spectroscopic Studies and Electronic Structure Description of the High Potential Type 1 Copper Site in Fungal Laccase: Insight into the Effect of the Axial Ligand. J. Am. Chem. Soc. 1999, 121, 7138-7149.

(8) Durao, P.; Bento, I.; Fernandes, A. T.; Melo, E. P.; Lindley, P. F.; Martins, L. O. Perturbations of the T1 Copper Site in the CotA Laccase from Bacillus subtilis: Structural, Biochemical, Enzymatic and Stability Studies. JBIC, J. Biol. Inorg. Chem. 2006, 11, 514.

(9) Rodgers, C. J.; Blanford, C. F.; Giddens, S. R.; Skamnioti, P.; Armstrong, F. A.; Gurr, S. J. Designer Laccases: a Vogue for HighPotential Fungal Enzymes? Trends Biotechnol. 2010, 28, 63-72.

(10) Galli, C.; Gentili, P. Chemical Messengers: Mediated Oxidations with the Enzyme Laccase. J. Phys. Org. Chem. 2004, 17, 973-977. 
(11) Morozova, O. V.; Shumakovich, G. P.; Shleev, S. V.; Yaropolov, Y. I. Laccase-Mediator Systems and their Applications: A review. Appl. Biochem. Microbiol. 2007, 43, 523-535.

(12) Rochefort, D.; Leech, D.; Bourbonnais, R. Electron Transfer Mediator Systems for Bleaching of Paper Pulp. Green Chem. 2004, 6, 14-24.

(13) Riva, S. Laccases: Blue Enzymes for Green Chemistry. Trends Biotechnol. 2006, 24, 219-226.

(14) Kunamneni, A.; Camarero, S.; García-Burgos, C.; Plou, F. J.; Ballesteros, A.; Alcalde, M. Engineering and Applications of Fungal Laccases for Organic Synthesis. Microb. Cell Fact. 2008, 7, 32.

(15) Mate, D. M.; Alcalde, M. Laccase: a Multi-Purpose Biocatalyst at the Forefront of Biotechnology. Microb. Biotechnol. 2017, 10, 1457-1467.

(16) Falk, M.; Blum, Z.; Shleev, S. Direct Electron Transfer Based Enzymatic Fuel Cells. Electrochim. Acta 2012, 82, 191-202.

(17) Xu, F. Oxidation of Phenols, Anilines, and Benzenethiols by Fungal Laccases: Correlation between Activity and Redox Potentials as well as Halide Inhibition. Biochemistry 1996, 35, 7608-7614.

(18) Xu, F.; Shin, W.; Brown, S. H.; Wahleithner, J. A.; Sundaram, U. M.; Solomon, E. I. A Study of a Series of Recombinant Fungal Laccases and Bilirubin Oxidase that Exhibit Significant Differences in Redox Potential, Substrate Specificity, and Stability. Biochim. Biophys. Acta, Protein Struct. Mol. Enzymol. 1996, 1292, 303-311.

(19) Xu, F.; Palmer, A. E.; Yaver, D. S.; Berka, R. M.; Gambetta, G. A.; Brown, S. H.; Solomon, E. I. Targeted Mutations in a Trametes villosa Laccase Axial Perturbations of the T1 Copper. J. Biol. Chem. 1999, 274, 12372-12375.

(20) Jones, S. M.; Solomon, E. I. Electron Transfer and Reaction Mechanism of Laccases. Cell. Mol. Life Sci. 2015, 72, 869-883.

(21) Monza, E.; Lucas, M. F.; Camarero, S.; Alejaldre, L. C.; Martínez, A. T.; Guallar, V. Insights into Laccase Engineering from Molecular Simulations: Toward a Binding-Focused Strategy. J. Phys. Chem. Lett. 2015, 6, 1447-1453.

(22) Lucas, M. F. t.; Monza, E.; Jírgensen, L. J.; Ernst, H. A.; Piontek, K.; Bjerrum, M. J.; Martinez, A. n. T.; Camarero, S.; Guallar, V. Simulating Substrate Recognition and Oxidation in Laccases: from Description to Design. J. Chem. Theory Comput. 2017, 13, 14621467.

(23) Osipov, E.; Polyakov, K.; Kittl, R.; Shleev, S.; Dorovatovsky, P.; Tikhonova, T.; Hann, S.; Ludwig, R.; Popov, V. Effect of the L499M Mutation of the Ascomycetous Botrytis aclada Laccase on Redox Potential and Catalytic Properties. Acta Crystallogr., Sect. D: Biol. Crystallogr. 2014, 70, 2913-2923.

(24) Zumarraga, M.; Dominguez, C. V.; Camarero, S.; Shleev, S.; Polaina, J.; Martinez-Arias, A.; Ferrer, M.; De Lacey, A. L.; Fernandez, V. M.; Ballesteros, A. Combinatorial Saturation Mutagenesis of the Myceliophthora thermophila Laccase T2Mutant: the Connection between the C-Terminal Plug and the Conserved 509VSG511 Tripeptide. Comb. Chem. High Throughput Screening 2008, 11, 807816.

(25) Marshall, N. M.; Garner, D. K.; Wilson, T. D.; Gao, Y.-G.; Robinson, H.; Nilges, M. J.; Lu, Y. Rationally Tuning the Reduction Potential of a Single Cupredoxin beyond the Natural Range. Nature 2009, 462, 113.

(26) Hong, G.; Ivnitski, D. M.; Johnson, G. R.; Atanassov, P.; Pachter, R. Design Parameters for Tuning the Type $1 \mathrm{Cu}$ Multicopper Oxidase Redox Potential: Insight from a Combination of First Principles and Empirical Molecular Dynamics Simulations. J. Am. Chem. Soc. 2011, 133, 4802-4809.

(27) Cambria, M. T.; Gullotto, D.; Garavaglia, S.; Cambria, A. In silico Study of Structural Determinants Modulating the Redox Potential of Rigidoporus lignosus and other Fungal Laccases. J. Biomol. Struct. Dyn. 2012, 30, 89-101.

(28) Hadt, R. G.; Sun, N.; Marshall, N. M.; Hodgson, K. O.; Hedman, B.; Lu, Y.; Solomon, E. I. Spectroscopic and DFT Studies of Second-Sphere Variants of the Type 1 Copper Site in Azurin: Covalent and Nonlocal Electrostatic Contributions to Reduction Potentials. J. Am. Chem. Soc. 2012, 134, 16701-16716.
(29) Mate, D.; García-Burgos, C.; García-Ruiz, E.; Ballesteros, A. O.; Camarero, S.; Alcalde, M. Laboratory Evolution of High-Redox Potential Laccases. Chem. Biol. 2010, 17, 1030-1041.

(30) Pardo, I.; Chanagá, X.; Vicente, A. I.; Alcalde, M.; Camarero, S. New Colorimetric Screening Assays for the Directed Evolution of Fungal Laccases to improve the Conversion of Plant Biomass. BMC Biotechnol. 2013, 13, 90.

(31) Iglesias, J.; Saen-Oon, S.; Soliva, R.; Guallar, V. Computational Structure-based Drug Design: Predicting Target Flexibility. Wiley Interdiscip. Rev.: Comput. Mol. Sci. 2018, 8, No. e1367.

(32) Gonzalez-Perez, D.; Molina-Espeja, P.; Garcia-Ruiz, E.; Alcalde, M. Mutagenic Organized Recombination Process by Homologous In Vivo Grouping (MORPHING) for Directed Enzyme Evolution. PLoS One 2014, 9, No. e90919.

(33) Christenson, A.; Shleev, S.; Mano, N.; Heller, A.; Gorton, L. Redox Potentials of the Blue Copper Sites of Bilirubin Oxidases. Biochim. Biophys. Acta, Bioenerg. 2006, 1757, 1634-1641.

(34) Dagys, M.; Laurynènas, A.; Ratautas, D.; Kulys, J.; Vidžiūnaitè, R.; Talaikis, M.; Niaura, G.; Marcinkevičiene, L.; Meškys, R.; Shleev, S. Oxygen Electroreduction Catalysed by Laccase Wired to Gold Nanoparticles via the Trinuclear Copper Cluster. Energy Environ. Sci. 2017, 10, 498-502.

(35) Reinhammar, B. R. M. Oxidation-Reduction Potentials of the Electron Acceptors in Laccases and Stellacyanin. Biochim. Biophys. Acta, Bioenerg. 1972, 275, 245-259.

(36) Xu, F. Effects of Redox Potential and Hydroxide Inhibition on the pH Activity Profile of Fungal Laccases. J. Biol. Chem. 1997, 272, 924-928.

(37) Shleev, S.; Andoralov, V.; Falk, M.; Reimann, C. T.; Ruzgas, T.; Srnec, M.; Ryde, U.; Rulícek, L. On the Possibility of Uphill Intramolecular Electron Transfer in Multicopper Oxidases: Electrochemical and Quantum Chemical Study of Bilirubin Oxidase. Electroanalysis 2012, 24, 1524-1540.

(38) Hosseinzadeh, P.; Marshall, N. M.; Chacón, K. N.; Yu, Y.; Nilges, M. J.; New, S. Y.; Tashkov, S. A.; Blackburn, N. J.; Lu, Y. Design of a Single Protein that Spans the Entire 2-V Range of Physiological Redox Potentials. Proc. Natl. Acad. Sci. U. S. A. 2016, $113,262-267$.

(39) Gunne, M.; Höppner, A.; Hagedoorn, P. L.; Urlacher, V. B. Structural and Redox Properties of the Small Laccase Ssl1 from Streptomyces sviceus. FEBS J. 2014, 281, 4307-4318.

(40) Brissos, V.; Pereira, L.; Munteanu, F. D.; Cavaco-Paulo, A.; Martins, L. O. Expression System of CotA-Laccase for Directed Evolution and High-Throughput Screenings for the Oxidation of High-Redox Potential Dyes. Biotechnol. J. 2009, 4, 558-563.

(41) Alcalde, M.; Bulter, T.; Arnold, F. H. Colorimetric Assays for Biodegradation of Polycyclic Aromatic Hydrocarbons by Fungal Laccases. J. Biomol. Screening 2002, 7, 547-553.

(42) Torres-Salas, P.; Mate, D. M.; Ghazi, I.; Plou, F. J.; Ballesteros, A. O.; Alcalde, M. Widening the $\mathrm{pH}$ Activity Profile of a Fungal Laccase by Directed Evolution. ChemBioChem 2013, 14, 934-937.

(43) Battistuzzi, G.; Borsari, M.; Loschi, L.; Righi, F.; Sola, M. Redox Thermodynamics of Blue Copper Proteins. J. Am. Chem. Soc. 1999, 121, 501-506.

(44) Hosseinzadeh, P.; Lu, Y. Design and Fine-tuning Redox Potentials of Metalloproteins Involved in Electron Transfer in Bioenergetics. Biochim. Biophys. Acta, Bioenerg. 2016, 1857, 557-581.

(45) Glazunova, O. A.; Polyakov, K. M.; Moiseenko, K. V.; Kurzeev, S. A.; Fedorova, T. V. Structure-function study of two new middleredox potential laccases from basidiomycetes Antrodiella faginea and Steccherinum murashkinskyi. Int. J. Biol. Macromol. 2018, 118, 406418.

(46) Salony; Garg, N.; Baranwal, R.; Chhabra, M.; Mishra, S.; Chaudhuri, T. K.; Bisaria, V. S. Laccase of Cyathus bulleri: structural, catalytic characterization and expression in Escherichia coli. Biochim. Biophys. Acta, Proteins Proteomics 2008, 1784, 259-268.

(47) Gromiha, M. M.; Pathak, M. C.; Saraboji, K.; Ortlund, E. A.; Gaucher, E. A. Hydrophobic environment is a key factor for the 
stability of thermophilic proteins. Proteins: Struct., Funct., Genet. 2013, $81,715-721$.

(48) Walter, R. L.; Ealick, S. E.; Friedman, A. M.; Blake II, R. C.; Proctor, P.; Shoham, M. Multiple Wavelength Anomalous Diffraction (MAD) Crystal Structure of Rusticyanin: a Highly Oxidizing Cupredoxin with Extreme Acid Stability. J. Mol. Biol. 1996, 263, $730-751$.

(49) Mateljak, I.; Rice, A.; Yang, K.; Tron, T.; Alcalde, M. The generation of thermostable fungal laccase chimeras by SCHEMARASPP structure-guided recombination in vivo. ACS Synth. Biol. 2019, in press.

(50) Kille, S.; Acevedo-Rocha, C. G.; Parra, L. P.; Zhang, Z.-G.; Opperman, D. J.; Reetz, M. T.; Acevedo, J. P. Reducing Codon Redundancy and Screening Effort of Combinatorial Protein Libraries Created by Saturation Mutagenesis. ACS Synth. Biol. 2013, 2, 83-92.

(51) Alcalde, M. Mutagenesis protocols in Saccharomyces cerevisiae by in vivo overlap extension. In: In vitro Mutagenesis Protocols, 3rd ed.; Bramman, J., Ed.; Methods in Molecular Biology 634; SpringerHumana Press: Totowa, NJ; pp 3-15; ISBN: 978-1-60761-6511.

(52) Mate, D. M.; Gonzalez-Perez, D.; Kittl, R.; Ludwig, R.; Alcalde, M. Functional Expression of a Blood Tolerant Laccase in Pichia pastoris. BMC Biotechnol. 2013, 13, 38.

(53) Mate, D. M.; Garcia-Ruiz, E.; Camarero, S.; Shubin, V. V.; Falk, M.; Shleev, S.; Ballesteros, A. O.; Alcalde, M. Switching from Blue to Yellow: Altering the Spectral Properties of a High Redox Potential Laccase by Directed Evolution. Biocatal. Biotransform. 2013, 31, 821.

(54) Tsujimura, S.; Kuriyama, A.; Fujieda, N.; Kano, K.; Ikeda, T. Mediated Spectroelectrochemical Titration of Proteins for Redox Potential Measurements by a Separator-less One-Compartment Bulk Electrolysis Method. Anal. Biochem. 2005, 337, 325-331.

(55) Jacobson, M. P.; Friesner, R. A.; Xiang, Z.; Honig, B. On the Role of the Crystal Environment in Determining Protein Side-Chain Conformations. J. Mol. Biol. 2002, 320, 597-608.

(56) Jacobson, M. P.; Pincus, D. L.; Rapp, C. S.; Day, T. J.; Honig, B.; Shaw, D. E.; Friesner, R. A. A Hierarchical Approach to all-atom Protein Loop Prediction. Proteins: Struct., Funct., Genet. 2004, 55, 351-367.

(57) Gordon, J. C.; Myers, J. B.; Folta, T.; Shoja, V.; Heath, L. S.; Onufriev, A. H++: a Server for Estimating $\mathrm{p} \mathrm{K}$ as and Adding Missing Hydrogens to Macromolecules. Nucleic Acids Res. 2005, 33, W368W371.

(58) Olsson, M. H.; SØndergaard, C. R.; Rostkowski, M.; Jensen, J. H. PROPKA3: Consistent Treatment of Internal and Surface Residues in Empirical p K a Predictions. J. Chem. Theory Comput. 2011, 7, 525-537.

(59) Friesner, R. A.; Banks, J. L.; Murphy, R. B.; Halgren, T. A.; Klicic, J. J.; Mainz, D. T.; Repasky, M. P.; Knoll, E. H.; Shelley, M.; Perry, J. K. Glide: a New Approach for Rapid, Accurate Docking and Scoring. 1. Method and Assessment of Docking Accuracy. J. Med. Chem. 2004, 47, 1739-1749.

(60) Halgren, T. A. Identifying and Characterizing Binding Sites and Assessing Druggability. J. Chem. Inf. Model. 2009, 49, 377-389.

(61) Bochevarov, A. D.; Harder, E.; Hughes, T. F.; Greenwood, J. R.; Braden, D. A.; Philipp, D. M.; Rinaldo, D.; Halls, M. D.; Zhang, J.; Friesner, R. A. Jaguar: a High-Performance Quantum Chemistry Software Program with Strengths in Life and Materials Sciences. Int. J. Quantum Chem. 2013, 113, 2110-2142.

(62) Pardo, I.; Santiago, G.; Gentili, P.; Lucas, F.; Monza, E.; Medrano, F. J.; Galli, C.; Martínez, A. T.; Guallar, V.; Camarero, S. Re-designing the Substrate Binding Pocket of Laccase for Enhanced Oxidation of Sinapic Acid. Catal. Sci. Technol. 2016, 6, 3900-3910.

(63) Santiago, G.; de Salas, F.; Lucas, M. F.; Monza, E.; Acebes, S.; Martinez, Á. T.; Camarero, S.; Guallar, V. Computer-Aided Laccase Engineering: Toward Biological Oxidation of Arylamines. ACS Catal. 2016, 6, 5415-5423.

(64) Borrelli, K. W.; Vitalis, A.; Alcantara, R.; Guallar, V. PELE: Protein Energy Landscape Exploration. A Novel Monte Carlo based Technique. J. Chem. Theory Comput. 2005, 1, 1304-1311.
(65) Cossins, B. P.; Hosseini, A.; Guallar, V. Exploration of Protein Conformational Change with PELE and Meta-Dynamics. J. Chem. Theory Comput. 2012, 8, 959-965.

(66) Kaminski, G. A.; Friesner, R. A.; Tirado-Rives, J.; Jorgensen, W. L. Evaluation and Reparametrization of the OPLS-AA Force Field for Proteins via Comparison with Accurate Quantum Chemical Calculations on Peptides. J. Phys. Chem. B 2001, B105, 6474-6487.

(67) Toukan, K.; Rahman, A. Molecular-Dynamics Study of Atomic Motions in Water. Phys. Rev. B: Condens. Matter Mater. Phys. 1985, 31, 2643.

(68) Martyna, G. J.; Tobias, D. J.; Klein, M. L. Constant Pressure Molecular Dynamics Algorithms. J. Chem. Phys. 1994, 101, 41774189.

(69) Nosé, S. A Unified Formulation of the Constant Temperature Molecular Dynamics Methods. J. Chem. Phys. 1984, 81, 511-519.

(70) Tuckerman, M.; Berne, B. J.; Martyna, G. J. Reversible Multiple Time Scale Molecular Dynamics. J. Chem. Phys. 1992, 97, 19902001.

(71) Essmann, U.; Perera, L.; Berkowitz, M. L.; Darden, T.; Lee, H.; Pedersen, L. G. A Smooth Particle Mesh Ewald Method. J. Chem. Phys. 1995, 103, 8577-8593. 